\title{
Children in 2077: Designing Children's Technologies in the Age of Transhumanism
}

$\begin{array}{ll}\text { Oğuz 'Oz' Buruk } & \text { Oğuzhan Özcan } \\ \text { oguz.buruk@tuni.fi } & \text { oozcan@ku.edu.tr } \\ \text { Gökçe Elif Baykal } & \text { Tilbe Göksun } \\ \text { elif.baykal@cc.au.dk } & \text { tgoksun@ku.edu.tr } \\ \text { Selçuk Acar } & \text { Güler Akduman } \\ \text { acars@buffalostate.edu } & \text { gulerakduman@gmail.com } \\ \text { Mehmet Aydın Baytaş } & \text { Ceylan Bessevli } \\ \text { baytas@chalmers.se } & \text { cbesevli17@ku.edu.tr } \\ \text { Joe Best } & \text { Aykut Coşkun } \\ \text { joseph.best@nottingham.ac.uk } & \text { aykutcoskun@ku.edu.tr } \\ \text { Hüseyin Uğur Genç } & \text { A. Baki Kocaballi } \\ \text { hgenc17@ku.edu.tr } & \text { baki.kocaballi@mq.edu.au } \\ \text { Samuli Laato } & \text { Cássia Mota } \\ \text { sadala@utu.fi } & \text { cassiamota@gmail.com } \\ \text { Konstantinos Papangelis } & \text { Marigo Raftopoulos } \\ \text { kpapangelis@me.com } & \text { marigo@strategicinnovationlab.com } \\ \text { Richard Ramchurn } & \text { Juan Sádaba } \\ \text { richard.ramchurn@ } & \text { sadaba@ehu.eus } \\ \text { nottingham.ac.uk } & \\ \text { Mattia Thibault } & \text { Annika Wolff } \\ \text { mattia.thibault@tuni.fi } & \text { annika.wolff@lut.fi } \\ \text { Mert Yldılı } & \\ \text { mertyıldı18@ku.edu.tr } & \end{array}$

Permission to make digital or hard copies of all or part of this work for personal or classroom use is granted without fee provided that copies are not made or distributed for profit or commercial advantage and that copies bear this notice and the full citation on the first page. Copyrights for components of this work owned by others than the author(s) must be honored. Abstracting with credit is permitted. To copy otherwise, or republish, to post on servers or to redistribute to lists, requires prior specific permission and/or a fee. Request permissions from permissions@acm.org. CHI '20 Extended Abstracts, April 25-30, 2020, Honolulu, HI, USA.

(C) 2020 Association for Computing Machinery.

ACM ISBN ISBN 978-1-4503-6819-3/20/04 ...\$15.00.

http://dx.doi.org/10.1145/3334480.3381821

\begin{abstract}
What for and how will we design children's technologies in the transhumanism age, and what stance will we take as designers? This paper aims to answer this question with 13 fictional abstracts from sixteen authors of different countries, institutions and disciplines. Transhumanist thinking envisions enhancing human body and mind by blending human biology with technological augmentations. Fundamentally, it seeks to improve the human species, yet the impacts of such movement are unknown and the implications on children's lives and technologies were not explored deeply. In an age, where technologies such as under-skin chips or brain-machine interfaces can clearly be defined as transhumanist, our aim is to reveal probable pitfalls and benefits of those technologies on children's lives by using the power of design fiction. Thus, main contribution of this paper is to create diverse presentation of provocative research ideas that will foster the discussion on the transhumanist technologies impacting the lives of children in the future.
\end{abstract}

\section{Author Keywords}

children, interaction design, transhumanism, design fiction, speculation, brain-machine interface, posthumanism, cyborg, augmented human, wearables 


\section{CCS Concepts}

-Human-centered computing $\rightarrow \mathrm{HCl}$ design and evaluation methods; Ubiquitous computing; Scenario-based design; Interaction design theory, concepts and paradigms;

\section{Introduction}

Tranhumanist thinking envisions that a new node in human evolution will come with technological enhancements that will augment the body and mind of the future human beings [14]. As Bostrom argues, transhumans are expected to possess enhanced abilities in terms of physical, sensory, and cognitive skills as well as a longer lifespan and emotional state $[11,10]$. Still, although the positive impacts of those kinds of enhancements are conceivable, there are many arguments standing against it by emphasizing how those technologies can impair the 'humanity' when it comes to equality [24], ethical applications, [20] biological definition of human [24] or procreative actions [1]. Therefore, development, implementation and the integration of those kinds of technologies to our lives are source of a heating debate while Brain-Machine Interfaces (BMI) [17], under-skin chips [23] or cyborgs such as Neil Harbisson are already a reality. Yet, those developments and debates rarely focus on the impact of those technologies on children albeit procreative liberty is seen as one of the drivers of transhumanist evolution [1]. In a future where technology is blended into the human body, what will the children be like? In this paper, we explore this topic through the five pillars of transhumanist enhancements; 1) intellectual capacity, 2) bodily functionality, 3) sensory modalities, 4) emotional capabilities (mood, energy, and self-control) and 5) life-span [10] that will be the possible results of advancements in technologies such as BMI, bodily implants or genetic modification.

To give a contemporary example on the enhancement of intellectual capacity, if BMI applications envisioned by the claims of Elon Musk's Neuralink [26] project come to be true, it is not hard to see a future where our brains will be implanted with chips to control the devices around us. Beyond that, it is also claimed that by reversing the process, it might be possible to download information from computers with NeuraLace technology [36]. We can anticipate that through these types of technologies, the information that would normally take 20 years to possess until graduating from the university, may be placed in our brains at once. In other words, we may face scenarios in which a 7-year-old child could obtain all the information they would normally have at the age of 23. Furthermore, according to the design speculations of Eisenberg, genetic modification technologies may allow to orient children's cognitive skills towards specific abilities (i.e., playing the piano) [13], which then result in virtuosi who outperform the most prominent artists of today at a very young age. While it is possible to envision that the first generation of these children might be the frontiers of transhumans to carry it to futures beyond what we can imagine now in terms of art, technology, philosophy and science, we also need to acknowledge the substantial risks in terms of ethics and also for the social development of these children. For example, gifted children of today who perform considerably better than their peers in certain cognitive skills -almost in the level of adults-, face behavioral disorders because of the incompatibilities between their cognitive versus socio-emotional development [8, 35]. In a society where children are cognitively enhanced and oriented towards different abilities, this incompatibility will possibly go beyond what we have experienced so far. This is only one of the examples which can reflect the problematic cases that will emerge should these technologies become prevalent.

Assuming that these advancements will be achieved and we will also face the consequences, our aim here is, by us- 
ing the power of design fiction [12, 9], to portray a future that reveals the pitfalls and threats that might be caused by these technologies and possible speculative research visions that will touch on the issues related to ethics and values as well as cautionary calls for the required regulations. On the other hand, we are also curious in what circumstances these types of technologies can help improve the quality of the children's lives. These inquiries also prompt to think what design research would focus on in terms of children's artifacts in the age of transhumanism. Our purpose is to encourage critical thinking on the topic, but also create speculative research ideas that can help us to understand how these technologies can help for an improved state of life. In that direction, main contribution of this paper is exploring the possible advances in transhumanist technologies designed for children and their consequences through speculative research ideas by giving voice to researchers from diverse disciplines within $\mathrm{HCl}$. This effort is particularly important, since the effects of such technologies on children were explored only by few studies $[13,18]$ and thereby, diversity of approaches are lacking but needed and crucial for constructing this sensitive topic.

To achieve creating a manuscript corresponding to the above concerns, we prepared a crowd-sourced paper contributed by 16 authors with thirteen fictional abstracts focusing on transhumanist technologies for children. The final form of this paper is similar to previous fictional abstract collections such as the speculative visions for $\mathrm{CHI} 2039$ by Baumer et al. [4] or by Bates et al. [3]. Fictional abstracts are especially useful for such uncharted topics because they allow exploration beyond utilitarianism by focusing on possible societal impacts [22]. Therefore, for initiating this action, we posted a Call for Abstracts [28] to various communication channels such as $\mathrm{HCl}$ and Design Mail Lists and related social media channels. We also pushed the cal through interpersonal connections. The call was posted on 04 Nov 2019 and the deadline for submitting abstracts was on 02 Dec 2019. In total, 13 abstracts were submitted to our call. The corresponding author (first author) collected the submitted abstracts in a shared document and other organizing authors (first five authors) commented on each abstract. Afterwards, comments were curated for authors, taking into account also 'Guidelines for Writing Fictional Abstracts [30]', then the abstracts were sent back to the authors for revisions. These revisions included the addition of figures, clarification of concepts, adjusting the language and the concepts to make them more suitable to the theme of the paper. Between 14 Dec 2019 and the submission deadline for alt.CHI 2020 (06 Jan 2010), organizing authors and abstract authors iterated through several revision cycles.

The resulting outcome of this collective effort is the thirteen fictional abstracts presented in the remainder of this paper. Abstracts address many different subjects such as social communication of transhuman children, their relationship with machines, transhuman play, virtual existence, climate change or inclusivity in such an age where everyone is distinctively-abled. Quite fitting to the primary aim of this paper, the collection of these abstracts reflects possible benefits of such technologies for children while also emphasizing the substantial challenges and risks.

\section{Harnessing Brain Elasticity of Children to Culti- vate Design Experts}

Samuli Laato, University of Turku, Turku, Finland

As humans, we need a thorough practical understanding of our limbic system and how it interfaces with digital enhancements to continue operating in society. To investigate whether and how the human brain could still add value to the design of solutions for teaching the bio-computational 
thinking, we run a comparative study with three groups: Al Designomator $(n=10)$, university faculty (experienced in using rapid $A$ l design interface) $(n=10)$ and adolescents (possessing brain-integration interface to rapid Al design) $(n=10)$. All groups worked on their design for a year with rapid Al prototyping. The artifacts from the groups were tested globally $(n=13750)$ with volunteer humans aged between 10-11 during spring 2077. Adolescent designers had on average the most iterations $(855,5)$ compared to faculty $(112,2)$ and Designomator $(1,0)$. The adolescent designers outperformed university faculty and Designomator, in creating solutions which appeal to their target audience. Yet, with regards to conceptual change among learners towards more efficient knowledge structures, the Designomator scored best before adolescents.

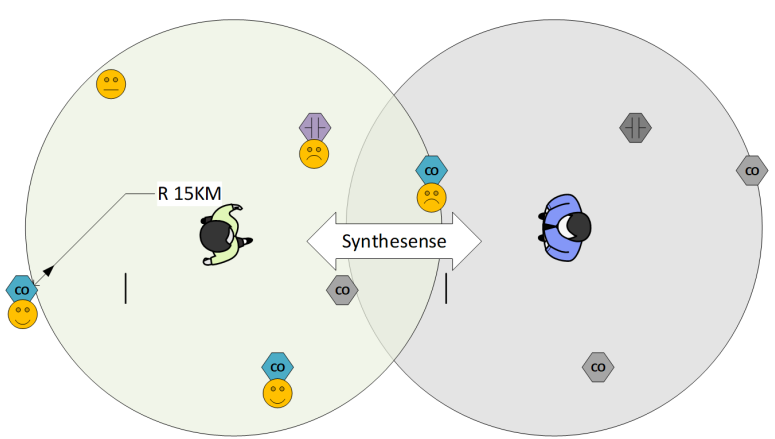

Figure 1: Synthesense - aligning the experiences of seventh sensors and senseless

\section{The AugKids are Blooming: Co-designing with Seventh Sensors}

Annika Wolff, LUT University, Lappeenranta, Finland

Since 2060, newborns from around the world have been augmented with implants that allow them to receive, process and to 'feel' data from environmental sensors in a 15kilometer radius (Figure 1). These unique AugKids - or 'sev- enth sensors' as they are affectionately known - grow to be highly empathic towards the world around them and care deeply about the environment. As they reach maturity and become old enough to participate in civil society, important questions emerge. How can technology support AugKids to fulfill their promise of designing a better future? This paper describes a cross-modal tool 'Synthesense' that allows the 'seventh sensors' and the 'senseless' to communicate about environmental data during co-design scenarios, creating common ground between different stakeholders (managers, engineers, designers, city planners from both the seventh sensor and senseless communities) participating in the process. We discuss the success of the tool in one co-design case study in urban regeneration of a local brickworks site. We reflect on the limitations of the technology in recreating the ineffable experience of qualia associated with these new senses.

\section{Exploring the Lived Experiences of High-School Students that Use the In-Class Attentiveness CR-XB Add-on Module in Their Neuro-Implants} Konstantinos Papangelis, Rochester Institute of Technology, Rochester, NY, USA

Schools requiring the students to have the in-class attentiveness CR-XB add-on module in their neuro-implants are becoming more and more common. The main argument for such a requirement is that studies have illustrated that the use of CR-XB addon correlates to high standardized test scores. What is notably missing from these studies is a deeper engagement with the lived experiences of students with the CR-XB addon. In this paper, we aim to address this lacuna by interviewing 57 high-school students about their experiences with the CR-XB addon. Our findings show that not only the students' view of these upgrades to their implants negatively but also that they affect their wellbe- 
ing and learning as they spent most of their in-class time is spent trying to produce a high attentiveness score and have to study after school to fully comprehend the taught topics. In the main, our study shows that the CR-XB add-on module significantly disrupts students' lives, and casts doubt into studies correlating the high scores with the in-class use of the CR-XB addon.

\section{Setting a framework for research on e-identities acceptance issues to assess critical physical life proprioception disorders}

e-ID: Emma Lenzi. 31, ph-ID: Juan Sádaba, 101, Peninsula of the Italian Alps, Sea Port of Trento, University of the Basque Country

The current common practice for virtual presencial meetings is a delicate subject to address, but given the critical amount of new cases of self-awareness and proprioception issues in young individuals, it is time to find a way to reconstruct the link between holograms or more advance e-presence situations and physical life. However, initial research is showing personality problems occurring not only in the physical activity of people at home while eworking or e-sport competing but it is getting harsher when e-personalities establish levels of relationship where both sides start neglecting the other's existence. This situation is often bidirectional and opens up many ethical questions on which of them should survive. One of my seminal papers related to this matter, pointed out '[that] lab-produced male gametes triggered an unexpected boom of e-gender re-assignations' [33]. Should we exclude underage children from e-relationships involving sex or business related transactions even in cases of excellent IQ top-up? Is gender crucial or not on e-personalities? Where to guide research to help children accept their own coexisting 'e' and 'ph' identities?

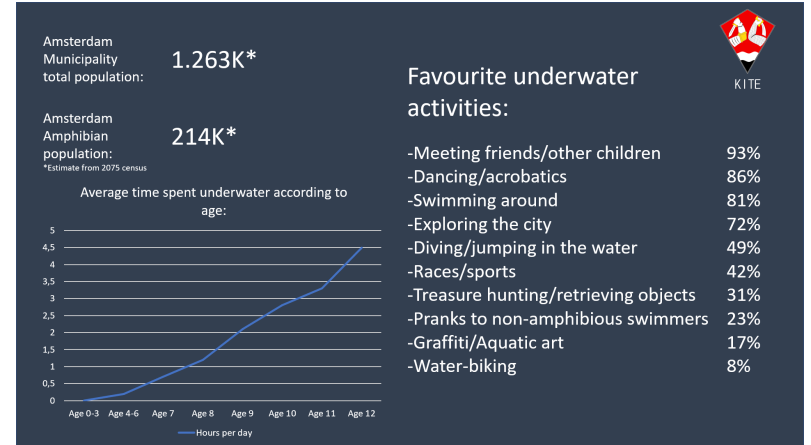

Figure 2: Detailed Results of the Deep Learning Survey

\section{Deep Learning: Child Development and Underwater Play Activities in Amsterdam} Mattia Thibault, KITE - Karelian Institute for Transhuman Education (formerly Tampere University, Finland)

Water-breathing technologies are today endemic in many costal areas as well as in several Sunken Nations (such as Maldives and Tuvalu). Due to the impossibility of installing water-breathing implants in adults, in 2065 the Dutch government declared that all new-borns in the Netherlands should undergo the procedure. This paper aims at analysing the impact of this legislation, notably the creation of a new generation of citizens using the city's canals as unsupervised playgrounds and spaces to explore. The paper will showcase the results of a survey dedicated to the new uses of public spaces made by the amphibian youth ( 50 participants, see Figure 2), and building on Hoorn's studies on the positive effects of underwater play [16], argue for the inclusion of semi-structured underwater activities, or "deep learning" in Dutch schools' curricula, underlining their potential benefits for the students in regard of their health, development, sociability and learning outcomes. 


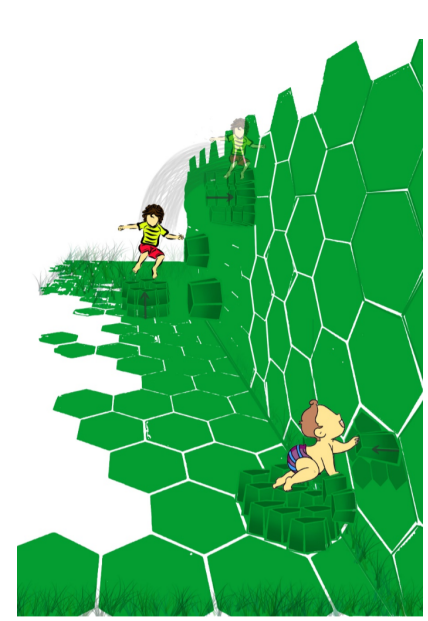

Figure 3: An example case of children interacting with shape-changing environments

\section{In-body Conversational Agents for Children:} A Systematic Review

A. Baki Kocaballi, Australian Institute of Health Innovation, Macquarie University, Sydney, Australia

In-body conversational agents (IBCAs) have been increasingly used to support children in their daily activities. IBCAs are conversational agents implanted in ear canals. We performed a systematic review of the works published in the last five years (2072-2077) focusing on children with IBCAs. We found 17 studies focusing on education, parental monitoring, play companions, and health. IBCAs were found to be significantly effective in personalized education and healthcare; however, two studies found that children tend to rely on their IBCAs to answer questions asked rather than their internalized knowledge. There have been mixed results in using IBCAs as play companions and parental monitoring tools. While children appeared to enjoy the constant availability of their IBCAs and the internal nature of communication, a few studies reported on (i) children's discomfort with the always-on feature of parental monitoring, (ii) their lack of control on parental access rights, (iii) their difficulties in managing their attention switching between IBCAs and other people, and (iv) the introverting effects of hyperpersonalization. Despite some positive outcomes associated with IBCAs in some domains, more research studies are needed to understand the unintended consequences of their use before their widespread adoption.

\section{Advisory analysis of Past Life Access for Neural Collective Sublimation (PLANCS)}

Richard Ramchurn, Joe Best, University of Nottingham, Nottingham, UK

The integration of Biological Human Computing led to Al Human Collective Psyche (HCP). Our paper reflects on
MERGE_REQUEST_27495 (PLANCS) and assesses group stability, Neuronal Messaging System (NMS) usage and adverse physiological effect on $(n=65536)$ subjects. PLANCS was a beta for children aged 13-17 which ran in September 2077. Over 6 nights the subjects lived several lifetimes drawn from ancestral DNA memories. The HCP's plan for global sustainability following the Paradise Wars (2060$66)$, is now focused on the attainment of harmonious coexistence; to removal of humanity's vestigial barbarism. PLANCS promised rapid mental and emotional growth to prepare for global evolution. We analysed PLANCS beta testers and a control group (each $n=32768$ ) from two former Paradise Zones over a 6-month period. We found exponential increases in complex empathy and multi-nodal communication frequency without detriment to IRL capabilities. Additionally, the PLANCS group consistently devised optimum solutions for collective survival in extrapolated simulations. In conclusion we advise redistribution of global governance to $16-24$ year-old PLANCS enabled beings.

\section{Reimagining Human Interaction with Nature: En- couraging Outdoor Play Through Shape Display Systems}

Güler Akduman, Kadir Has University, Istanbul, Turkey

Play makes us human. It is a right, a need and a way of communication. Today's children spend most of their time indoors using domestic play technologies which provide them sensory-rich environments and satisfy their mental and physical needs in an effective way. For children who are accustomed to play in environments full of external stimuli, natural play is not a satisfying activity. As a result, most of them are alienated to nature or even biophobic. This study explores the ways to encourage outdoor play and contact with nature through shape display technologies which combine natural elements and an interactive 
system detecting and reacting to human actions. Shape changing systems 3 enrich the ways to interact with nature and provide a wide variety of play activities which cannot be replicated indoors. This paper aims to form guidelines for using this enabling technology in the design of transforming outdoor play spaces.

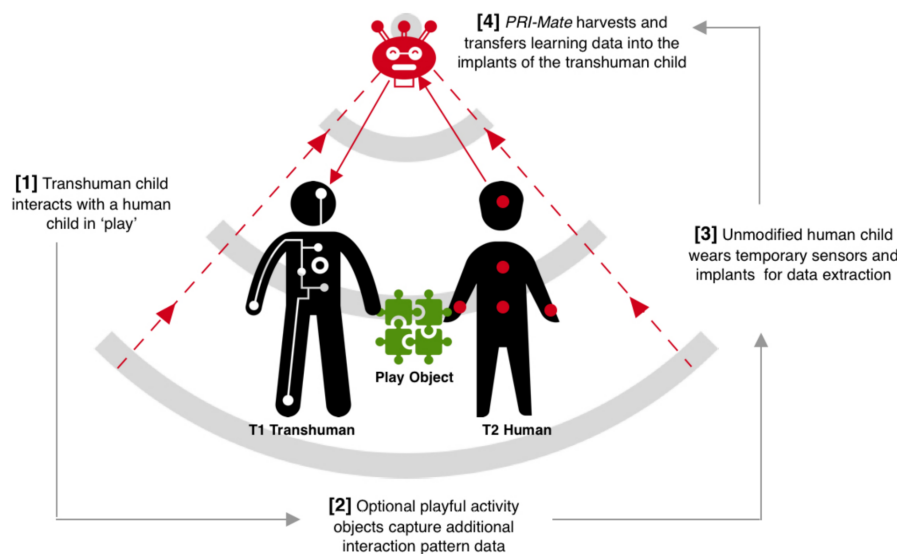

Figure 4: Schematic of PRI-Mate harvesting and transferring learning data

\section{PRI-Mate: Replicating Human Creative Intelligence for Transhuman Children}

Marigo Raftopoulos, Strategic Innovation Lab, Australia

Advances in transhumanist technologies have significantly enhanced the cognitive performance of children in Tier 1 socioeconomic communities ( $\mathrm{T} 1$ ) driven by devices such as brain-neural network connectivity implants and optical augmented reality lenses. However, there has been a corresponding decline in the creative capability scores of $\mathrm{T} 1$ transhuman children relative to human children from lower
Tiers (T2+) with less technological enhancements. This capability gap has been widening since 2060 and has been attributed to failures of Al to replicate human creative intelligence. This paper presents the laboratory experiments of PRI-Mate (Figure 4), an android that accompanies transhuman children during mixed-tier creative interactions, formerly known as 'play'. Through observation and interrogation, PRI-Mate harvests data from neurological, physiological, emotional and behavioural scans of unmodified T2+ human children to map and codify their creative capability. PRI-Mate provides the inference engine and skills transfer into the implants of $\mathrm{T} 1$ transhuman children through direct neural stimuli.

\section{Transhumanist Interspecies Children Inventions and Associated Intellectual Protection Rights Cássia Mota, Brazil's National Institute of Industrial Prop-} erty, ostraobservatorio.com, Brasília, Brazil

After the collapse of the International Intellectual Property System around the 2040's due to its inability to manage so different types of intelligences, cognition bonds seemed to be the answer to mostly all non-linear creations made by transhumanist interspecies individuals. The concept of cognition bond was founded on the idea of paying back investments on the development of certain abilities on interspecies children. Those investments rely on intellectual trusts, that also speculate for new creative bids. The most popular archetype example of intellectual trust was the case of the planned baby human stomatopoda paintings financed by a group of artists from Sugarloaf Islands (Figure 5), back in 2047. But we see now a problem when the earnings of a fund can only be collected two generations after the initial investments. This leads us to some questions: how cognition bonds will pay back investors of collective interspecies inventions? How to refund young populations reminiscent 

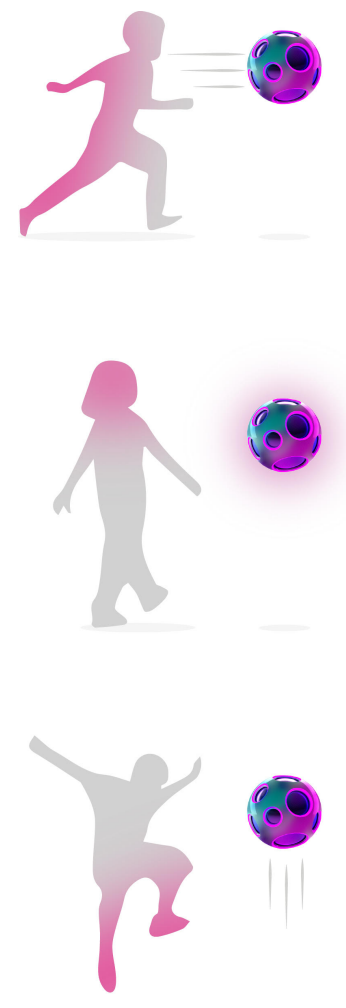

Figure 6: (From top to down) 1) CoEqual accelerates itself for the child who has enhanced speed. 2) CoEqual changes its temperatures to hide for the child who has thermal vision. 3) CoEqual elevates itself for the child who has enhanced jumping ability. of elder generations investments on cognition? This doctoral consortium proposal aims to explore those questions by drawing some conjectures.

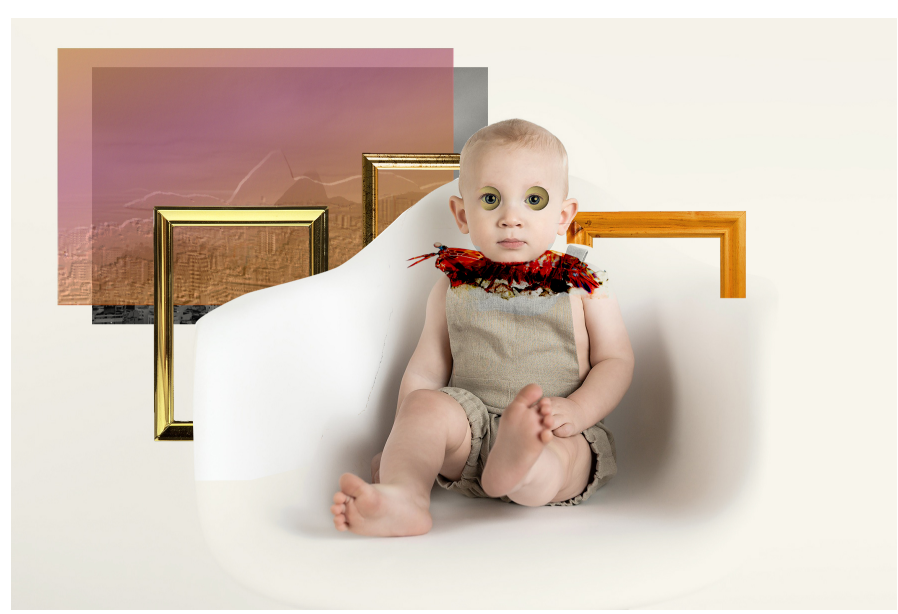

Figure 5: An example of Intellectual Trust case

\section{CoEqual: Re-visiting the Challenge for} Transhuman-Children's Collaborative Play Ceylan Beşevli, Mert Yıldız, Hüseyin Uğur Genç, Aykut Coşkun, Koç University-Arçelik Research Center for Creative Industries, Istanbul, Turkey

With the advancements of transhumanist technologies, children have more capabilities (e.g., enhanced vision, powered exoskeletons) compared to past generations. Since parents choose different advancement procedures on children, a gulf of execution has emerged in their social interactions with peers. Specifically, children are no longer able to play together, as a challenge for one child (e.g., running fast) is not a challenge to the other. We looked at 12 universal children's games, which are played collectively, of the 20th century (e.g., hide-and-seek, sack race) and analyzed their game mechanics. Our analysis showed that blocking an ability (e.g., limiting vision) is the main factor to create a challenge for the children. Deriving on this motivation, we present "CoEqual (Figure 6)", a game for exploring Transhuman-Child-Play Interaction (tCPI) that fosters 'inclusive' challenges which can be adapted to children's individual abilities for generating collaborative game dynamics.

\section{Enabling Matrix Access for Prepubescent Chil- dren with a Novel Sensor-Mixer Architecture}

Mehmet Aydın Baytaş, Chalmers University of Technology, Gothenburg, Sweden

As of 2077 , more than $10 \%$ of the world's population have taken up permanent residence in the Matrix. With Scientific Consensus in favor of the Matrix as a safe, sustainable, longevous and rewarding way of life, adoption is expected to grow. In turn, the scalability of the Matrix towards universal coverage is predicated on two important and interconnected challenges: reproduction in the Matrix and pre-adulthood interface compatibility. The latter of these challenges has been addressed in recent $\mathrm{HCl}$ research demonstrating interface system prototypes for late adolescents. Building on this work, we report on an interface system intended for compatibility with prepubescent children, validated through standard C-protocol trials. Our prototype is built around a novel sensor-mixer architecture that can maintain closed-loop liquid medium control during periods of rapid change in the human body. If deployed at scale, our design may enable Matrix access for more than seven million new families. 


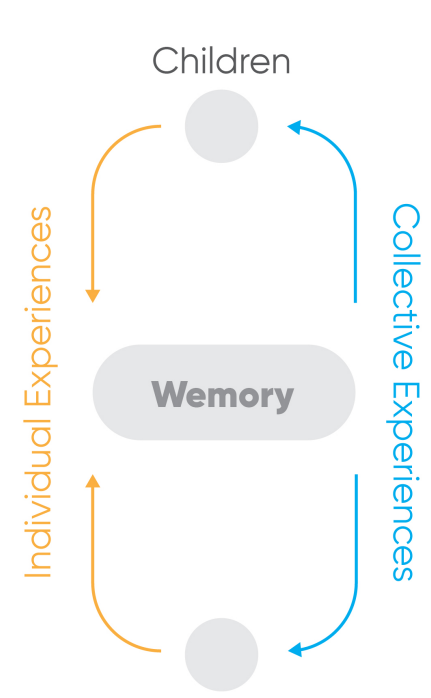

Parents

Figure 7: Individual experiences from each family member are gathered and Wemory creates new "collective" experiences.

\section{Wemory: Designing for Social Bonding in Today's Families}

Ceylan Beşevli, Mert Yıldız, Hüseyin Uğur Genç, Aykut Coşkun, Koç University-Arçelik Research Center for Creative Industries, Istanbul, Turkey

Children born in the last decade have been subjected to neural advancement procedures such as enhanced memory capacity. While this procedure was to make knowledge last longer in children's brains, an unexpected issue was its detrimental effect on language and social relationships. Since knowledge became constantly available in children's memory, they communicate less with their caregivers to exchange information that results in poor social bonding with their parents. This issue poses important implications for the future of parent-child relationships. To address this, we conducted six focus groups (three transhuman $(n=13)$ families and three human families $(n=12)$ ) to gain a deep understanding of their methods for family bonding. Based on our analysis, we identified four themes and translated them into design directions. By covering these directions, we introduce 'Wemory' (Figure 7) which creates particular memories for each family member that make up a collective memory for long-term family relations.

\section{Reflections to Future}

Abstracts collected here reflect a wide array of outcomes which can be the results of transhuman technologies for children when they become prevalent in the society. In this section, we will present a brief summary of the topics conveyed by this collection and propose some research questions that might be of interest to the parties which are involved in body-integrated technologies from wearables to medical implants which aim at improving human skills and conditions. In this section, we cited each abstract's fictional future reference, as it is a convention [30] that makes writing fictional abstract papers fun and interesting.

Some of the abstracts pointed out the social structure that will possibly be transformed by transhumanist technologies and also proposed new applications and interfaces that could be a cure to the problems that will arise as a result of this new structure. Examples include conflicts between physical and e-identities [34], introverting effects of in-body conversational agents [19], lack of harmony between Al and human minds [32], the challenge of producing inclusive games for distinctly-abled children [7] and degradation of in-family social interactions due to the lack of need for information exchange [6]. Some of the abstracts left answers to those questions open-ended while some others tried to come up with solutions for particular problems.

Effects of transhumanism technologies on the adaptation to the changing society and natural environment was also one of the common topics. In that sense, abstracts included an ideation on school curricula focusing on "deep learning" in underwater [37], children who are highly empathetic towards the environment due to their nature-bind sensations [38], new technologies for children who could not adapt to the natural environment because of disproportionate indoor activities due to the dissatisfaction from the lack of stimuli provided by nature [2], and adaptation technologies to the virtual layers of life, known as Matrix [5]!

Another prevalent topic was the privacy and the security issues that might impact the lives of children. Problematic cases came up as monitoring of children activities by authorities such as school management [29] or by their families [19]. Another abstract focused on how to protect ideas in an age when the earth would adorned with the creations of transhuman interspecies [25], inspired by Donna Haraway's When Species Meet [15]. 
Transformation of creative activities has also been the main focus for a few abstracts. Analyzing the creative orientation differences between human, transhuman and Al designers [21], tools that can enhance the communication between psychophysiologically enhanced children and "senseless" humans in co-design sessions [38], and interfaces that can help transhuman children to keep up with their nonaugmented peers [31] were the orientations of these abstract.

Abstracts in this paper put forth speculative research ideas that could help imagine scenarios around the questions we asked in our Call for Abstracts [28] such as "What kind of individual and social structure do we have in 2077?", "What is the problematic cases of transhumanist technology applied to children?", "How does the parent and child interaction change?", "How do the learning processes change?", "What and who are the mediators of learning?", "What might be the artifacts for this new generation of enhanced children?", "How is education and educational technology transformed?", "How do we involve these children in the design of transhumanist technologies as stakeholders?", "How to ensure a transparent process, inclusive participation and openness in transhumanist technology design?"

Those abstracts also created many other questions including "How can transhumanist technology help children adapt to the transforming social and natural context?" , "How can the relationships between augmented children and nonaugmented people be facilitated?", "What does inclusivity mean among transhuman children?", "How should we regulate cognitive enhancements and in-body agents for retaining the well-being of children?" or "Is intellectual property an outdated concept and how is it replaced?"

Rather than trying to present a detailed analysis of those abstracts, we aim to provide a summary around the mutual themes and research questions they raised. We specifically averted from doing a detailed analysis because the collected abstracts may not represent the entire field, although they propose quite distinct scenarios by authors from a wide array of disciplines within $\mathrm{HCl}$. Therefore, despite the effort of reflecting on the curiosity points that can be important for us, interpreting the results and forming new questions are left to readers. These abstracts could (hopefully) also inspire readers to take a step further and deploying them in the form of design fiction probes [27]. We end this piece with a final question which is the ultimate aim of this collection together with most design fiction papers: What do these abstracts tell us about the today's body and mind related technologies for children?

\section{After Review}

Our paper created interesting ideas and questions presented by alt.CHI commenters. These include reviewing past predictions about today's technologies through using these abstracts as a lens or quite interesting questions that are associated with today's ways of using technology by referring to the topics of some abstracts. These comments are also published alongside the paper, and they enhance the narrative of paper while also showing that our provocations can lead to very valuable questions about today's technologies and their relation to children.

\section{Acknowledgements}

Year 2077 is an attribution to the game Cyberpunk 2077 which depicts a fictional world in which the transhumanist technologies have an immense impact on humanity. This project has received funding from the European Union's Horizon 2020 research and innovation programme under the Marie Sklodowska-Curie grant agreement No 833731, WEARTUAL project. 


\section{REFERENCES}

[1] Nicholas Agar. 2007. Whereto Transhumanism?: The Literature Reaches a Critical Mass. The Hastings Center Report 37, 3 (2007), 12-17.

[2] Güler Akduman. 2077. Reimagining Human Interaction with Nature: Encouraging Outdoor Play Through Shape Display Systems (Forthcoming). In $\mathrm{CHI}$ '77 Proceedings of the 2077 Annual Conference on Human Factors in Computing Systems.

[3] Oliver Bates, Christian Remy, Callum Nash, and Ben Kirman. 2019. The Future of Techno-disruption in Gig Economy Workforces: Challenging the Dialogue with Fictional Abstracts. In Proceedings of the Halfway to the Future Symposium 2019 (HTTF 2019). ACM, New York, NY, USA, Article 32, 4 pages. DOI : http://dx.doi.org/10.1145/3363384.3363476

[4] Eric PS Baumer, June Ahn, Mei Bie, Elizabeth M Bonsignore, Ahmet Börütecene, Oğuz Turan Buruk, Tamara Clegg, Allison Druin, Florian Echtler, Dan Gruen, and others. 2014. CHI 2039: speculative research visions. In CHI'14 Extended Abstracts on Human Factors in Computing Systems. ACM, 761-770.

[5] Mehmet Aydın Baytaş. 2077. Enabling Matrix Access for Prepubescent Children with a Novel Sensor-Mixer Architecture (Forthcoming). In CHI '77 Proceedings of the 2077 Annual Conference on Human Factors in Computing Systems.

[6] Ceylan Beşevli, Mert Yıldız, Hüseyin Uğur Genç, Aykut Coşkun, and Oğuzhan Özcan. 2077a. CoEqual: Re-visiting the Challenge for Transhuman-Children's Collaborative Play (Forthcoming). In $\mathrm{CHI}$ '77 Proceedings of the 2077 Annual Conference on Human Factors in Computing Systems.
[7] Ceylan Beşevli, Mert Yıldız, Hüseyin Uğur Genç, Aykut Coşkun, and Oğuzhan Özcan. 2077b. Wemory: Designing for Social Bonding in Today's Families (Forthcoming). In CHI '77 Proceedings of the 2077 Annual Conference on Human Factors in Computing Systems.

[8] Nancy Zimmerman Bickley. 2001. The social and emotional adjustment of gifted children who experience asynchronous development and unique educational needs. (2001).

[9] Mark Blythe. 2014. Research through design fiction: narrative in real and imaginary abstracts. In Proceedings of the SIGCHI Conference on Human Factors in Computing Systems. ACM, 703-712.

[10] Nick Bostrom. 2005. Transhumanist values. Journal of philosophical research 30, Supplement (2005), 3-14.

[11] Nick Bostrom. 2008. Why I want to be a posthuman when I grow up. In Medical enhancement and posthumanity. Springer, 107-136.

[12] Anthony Dunne and Fiona Raby. 2013. Speculative everything: design, fiction, and social dreaming. MIT press.

[13] Michael Eisenberg. 2017. The binding of Fenrir: Children in an emerging age of transhumanist technology. In Proceedings of the 2017 Conference on Interaction Design and Children. ACM, 328-333.

[14] Joel Garreau. 2006. Radical evolution: the promise and peril of enhancing our minds, our bodies-and what it means to be human. Broadway.

[15] Donna J Haraway. 2013. When species meet. Vol. 3. U of Minnesota Press. 
[16] M Hoorn. 2075. Underwater play and physical activity in children and youth: a systematic review (Forthcoming). New archives of pediatrics \& adolescent medicine 183, 3 (2075), 664-672.

[17] InteraXon. 2019. Muse Headband. (2019). https://choosemuse.com

[18] Mary Beth Klinger and Teresa L Coffman. 2019. Transforming the Classroom Experience Through Transhumanism: Education as the Learning Organization. In Handbook of Research on Learning in the Age of Transhumanism. IGI Global, 134-156.

[19] A. Baki Kocaballı. 2077. In-body Conversational Agents for Children: A Systematic Review (Forthcoming). In $\mathrm{CHI}$ '77 Proceedings of the 2077 Annual Conference on Human Factors in Computing Systems.

[20] Tom Koch. 2010. Enhancing who? Enhancing what? Ethics, bioethics, and transhumanism. Journal of medicine and Philosophy 35, 6 (2010), 685-699.

[21] Samuli Laato. 2077. Harnessing Brain Elasticity of Children to Cultivate Design Experts (Forthcoming). In CHI '77 Proceedings of the 2077 Annual Conference on Human Factors in Computing Systems.

[22] Joseph Lindley and Paul Coulton. 2016. Pushing the limits of design fiction: the case for fictional research papers. In Proceedings of the $2016 \mathrm{CHI}$ Conference on Human Factors in Computing Systems. ACM, 4032-4043.

[23] Alexandra Ma. 2018. Thousands of people in Sweden are embedding microchips under their skin to replace ID cards. (2018).

https://www.businessinsider.com/swedish-people- embed-microchips-under-skin-to-replace-idcards $-2018-5$ ? $r=U S\{\&\} I R=T$.

[24] MJ McNamee and SD Edwards. 2006.

Transhumanism, medical technology and slippery slopes. Journal of Medical Ethics 32, 9 (2006), 513-518.

[25] Cássia Mota. 2077. Transhumanist Interspecies Children Inventions and Associated Intellectual Protection Rights (Forthcoming). In $\mathrm{CHI}$ '77 Proceedings of the 2077 Annual Conference on Human Factors in Computing Systems.

[26] Neuralink. 2019. Neuralink. (2019). https://www. neuralink.com

[27] Renee Noortman, Britta F Schulte, Paul Marshall, Saskia Bakker, and Anna L Cox. 2019. HawkEye-Deploying a Design Fiction Probe. In Proceedings of the $2019 \mathrm{CHI}$ Conference on Human Factors in Computing Systems. ACM, 422.

[28] Oğuzhan Özcan, Oğuz 'Oz' Buruk, Gökçe Elif Baykal, Tilbe Göksun, and Selçuk Acar. 2019. CALL FOR ABSTRACTS - ALT.CHI 2020 | CHILDREN IN 2077: DESIGNING CHILDREN'S TECHNOLOGIES IN THE AGE OF TRANSHUMANISM. (2019).

https://www .tut.fi/Gamification/2019/11/06/ call-for-abstracts-alt-chi-2020-children-in2077-designing-childrens-technologies-in-theage-of-transhumanism/.

[29] Konstantinos Papangelis. 2077. Exploring the Lived Experiences of High-SchoolStudents that Use the In-Class AttentivenessCR-XB Add-on Module in Their Neuro-Implants (Forthcoming). In $\mathrm{CHI}$ '77 Proceedings of the 2077 Annual Conference on Human Factors in Computing Systems. 
[30] Daniel Pargman, Elina Erikkson, Rob Comber, Ben Kirman, and Oliver Bates. 2018. Guidelines for Fictional Abstracts. (2018).

https://futuresnordichi. wordpress. com/2018/05/ 22/guidelines-for-fictional-abstracts/

[31] Marigo Raftopoulos. 2077. PRI-Mate: Replicating Human Creative Intelligence for Transhuman Children (Forthcoming). In CHI '77 Proceedings of the 2077 Annual Conference on Human Factors in Computing Systems.

[32] Richard Ramchurn and Joe Best. 2077. Advisory analysis of Past Life Access for Neural Collective Sublimation (PLANCS)(Forthcoming). In $\mathrm{CHI}$ '77 Proceedings of the 2077 Annual Conference on Human Factors in Computing Systems.

[33] Juan Sádaba. 2069. Artificial Sex Intelligence, a Compilation of Reference Cases. Between Proprioception and Self-Awareness (Forthcoming). MIT Sex Intelligence Review 23, 1 (2069).

[34] Juan 'Emma Lenzi' Sádaba. 2077. Setting a framework for research on e-identities acceptance issues to assess critical physical life proprioception disorders (Forthcoming). In $\mathrm{CHI}$ '77 Proceedings of the 2077 Annual Conference on Human Factors in Computing Systems.

[35] Linda Kreger Silverman. 1997. The construct of asynchronous development. Peabody Journal of Education 72, 3-4 (1997), 36-58.

[36] Susan Fourtané. 2018. Neuralink: How the Human Brain Will Download Directly from a Computer. (2018). https://interestingengineering. com/neuralinkhow-the-human-brain-will-download-directlyfrom-a-computer.

[37] Mattia Thibault. 2077. Deep Learning: Child Development and Underwater Play Activities in Amsterdam (Forthcoming). In $\mathrm{CHI}$ ' 77 Proceedings of the 2077 Annual Conference on Human Factors in Computing Systems.

[38] Annika Wolf. 2077. The AugKids are blooming: co-designing with seventh sensors (Forthcoming). In $\mathrm{CHI}$ '77 Proceedings of the 2077 Annual Conference on Human Factors in Computing Systems. 